\title{
Effectiveness of pyridoxin in reducing symptoms of anxiety pre menstrual syndrome in adolescent
}

Siti Nurunniyah ${ }^{1}$, Eva Nurinda ${ }^{2}$

${ }^{1}$ Departement of midwifery, Alma Ata University, ${ }^{2}$ Departement of pharmacy, Alma Ata University

DOI: http://dx.doi.org/10.19106/JMedScieSup0050012018021

\section{ABSTRACT}

Pre menstrual syndrome (PMS) affects women's quality of life, social and economic performance. The other study discovered that $23-31 \%$ of reproductive aged women experience PMS to a degree that affects their daily acivity. Symptoms of pre menstrual syndrome (PMS) are divided into 4 types, namely type A for anxiety, type $C$ for craving (hungry), type $\mathrm{D}$ for depression, and type $\mathrm{H}$ for hyperhydration (liquid stockpiling). Type A is commonly unrecognnized in Indonesia. Symptoms of type A consist of anxiety, irritability, labilty, and nerves tense. It is important to know how to reduce the symptoms. This study aims to determine the effectiveness of pyridoxin in reducing symptoms of pre menstrual syndrome (PMS) and the most resolvable type of symtom. There was an effect of using pyridoxine to reduce PMS. It known from the significance value of t-test that was 0.000 . The type of PMS with the highest symptom reduction was PMS type A, because pyridoxine could increase stability estrogen and progesterone activity. Anxiety pre menstrual syndrome probably caused by unstable hormone.

Keywords: Pre menstrual syndrome - Pyridoxin- PMS type A 